\title{
IMAGENS DE VIOLÊNCIA E JOGOS PERIGOSOS, VULGARIZAÇÃO DA BARBÁRIE E PROJEÇÕES DE CENAS SOCIAIS? ${ }^{1}$
}

\author{
Ana Luiza Carvalho da Rocha \\ Cornelia Eckert \\ “É uma maravilha antropológica. Precisamente por sua adequação em projetar em espetáculo uma imagem \\ percebida como reflexo exato da vida real." \\ (Edgar Morin, Le cinéma ou l'homme imaginaire)
}

Nos sistemas informacionais dominantes, as discursividades a partir de percepções generalizadas sobre a violência no mundo urbano contemporâneo dramatizam de forma negativa um processo de personalização configurada por uma lógica hiperindividualista numa sociedade onde triunfa a comunicação altamente mediatizada. Neste cenário planetário, refletir sobre a violência é problematizar a complexa tarefa de tecer as identidades sociais e sociabilidades locais/globais na trágica relação dos valores e concepções éticas de tempos acelerados, espaços virtualizados, reciprocidades desencantadas, comunicações banalizadas e humanização desubstancializada.

Nestas enunciações são engendradas imagens de uma violência contemporânea numa visibilidade total, produzidas por uma banalização do crime e da ameaça extremada, configurando esta des-ordem como deslegítima e causadora das crises e riscos consubstanciais à modernidade e à supremacia ideológica do individualismo.

Pensar o indivíduo moderno implica em situá-lo, pois, no processo de desocialização que o libera das ligações coletivas e rituais (reciprocidade) para construir-se enquanto sujeitos autônomos num face-à-face (inter-subjetividade) independente dos modelos sociais preestabelecidos. Trata-se do mesmo sistema de idéias que conformam a representação democrática, pois, individualista, que produz suas próprias ambigüidades e perversidades. Em nome de um corpo social, discursividades são produzidas sobre as "falhas" de civilidade dos comportamentos que hiper valorizam a atomização social e sobre a emergência do desafeto aos códigos ideais do contrato social, à legalidade e à liberdade.

Nas significações identificáveis da violência contemporânea, tem sido comum associar à produção de imagens e programas vinculados aos meios de comunicação de massa (televisão e cinema, por exemplo) o aumento do índice de agressividade, sadismo, brutalidade e criminalidade em nossas sociedades, numa espécie de "caça às bruxas" ao estilo do que

\footnotetext{
${ }^{1}$ Publicado na REVISTA DO GEEMPA, Porto Alegre Julho 99 número 7: "A não-aprendizagem: violência instituída", Editora Pallotti. 1999. P. 60 à 71.
} 
ocorreu no período das perseguições religiosas, na Idade Média, numa clara alusão aos efeitos diabólicos que tais tecnologias provocam em todos aqueles que com elas entra em contato.

Assimilando genericamente a violência, jornalistas, psicólogos, pedagogos, psicopedagogos, médicos, cientistas sociais, num tom analítico ameaçador, tentam em vão associar o desencadeamento da violência na vida cotidiana dos grandes centros urbanos às imagens veiculadas por programas de televisão, publicidade e filmes. Em sua maioria, partem do suposto de que o mero consumo de tais produtos culturais não apenas estimula, mas determina a escalada dos atos violentos no corpo da vida social. Assim, além de viciar o público infantil e adolescente em práticas imorais e degradantes, para desgraça de pais e educadores, à mídia, para piorar o quadro catastrofista, é acusada de ser fonte de inspiração para prática de atos brutais tais como assassinatos de pais por filhos, chacinas de alunos em sala de aula por colegas de turma, mortes de mendigos, usos de armas de fogo indiscriminado, etc, limitando-se a procurar no interior da subjetividade do indivíduo consumidor das imagens, o sentido da violência.

Com a perda da sua força simbólica no valor da honra e do sangue (categorias holísticas) próprias das civilizações tradicionais, a violência hoje perde progressivamente toda significação "positiva" na mesma proporção em que assistimos ao aumento da sensibilidade no âmbito do processo de controle das emoções sugeridas por Norbert Elias, por um aumento de auto-reflexibilidade da sociedades dos indivíduos.

Acusa-se a estética da violência proposta pela mídia como enraizadora de estímulos de destruição e agressão por parte dos jovens, de criminalidade por parte das "camadas perigosas", sem, entretanto, referenciar à correlata representação delegada da violência, seja pelo Estado, através de seu sistema repressivo, seja pelas distorções econômicas, geradoras de discriminação racial e estigmação da pobreza na vida social.

Na condição moderna ou pós-moderna, a crescente deslegitimação das práticas descontroladas, é proporcional à representatividade da violência mediada pelos meios de comunicação de massa de danosa, considerada fonte do mal estar da desagregação de nossa civilização contemporânea.

Importa aqui esclarecer que o espetáculo de violência hiperrealista não nos parece capaz de traduzir a natureza intrínseca da violência na modernidade. Por outro lado, não estamos como consumidoras, fazendo uma apologia de produções de ação do tipo "banhos de sangue", "socos e pontapés”, “estripações e quebra-costelas”. Propomos refletir, como antropólogas, a produção e o consumo de tais produtos culturais sem medo de, nesta caminhada, enfrentar os 
pré-conceitos e pré-juízos que tanto tem orientado, com desconfiança desarrazoada, a análise dos meios de comunicação nos dias de hoje.

Conforme aponta com pertinência L.E. Soares², "na academia, pelo menos no contexto brasileiro, ser pessimista é sinônimo de seriedade e responsabilidade intelectual", assim, pois, é que este artigo pode vir a ser interpretado, aqui, de forma equivocada como uma defesa de tais produtos culturais por negarmos a operar o conhecimento da violência, mediada pelos meios de comunicação, de forma reducionista ou unidimensional, não reforçando, necessariamente, um diagnóstico negativo e pessimista do mass media.

A defesa dos meios de comunicação neste artigo é tecida no sentido de nossa convicção da presença de distorções ideológicas no debate sobre a violência em geral e, em particular na escola, distorções que beiram à paranóia social sem pulverizar esta noção em formas diferenciadas de experiência e percepção. Porque direcionar o discurso sobre a violência escolar às ações físicas e energéticas acometidas por jovens, sem relacionar aí a fragilidade de laços sociais, as deficiências de ensino-orientação, as políticas de seleção e avaliação nem sempre conectadas com as expectativas de egalidade e justiça demandadas, a desfiliação à pertencimentos sociais que os qualifiquem como sujeitos jurídicos e morais, e, sobretudo a possível ausência de referentes sociais e redes reais de pedagogização (socialização a partir de experiências com significação para os sujeitos se auto-conceberem no mundo).

Buscamos elucidar nosso posicionamento sobre a natureza subjetiva da violência, um sentimento do que é, e do que pode vir a ser, a exposição de experimentar o mundo exterior como desconectado e imprevisível: "a violência nesse quadro é sempre o outro nome para designar a desigualdade na falta de ligação social".

Em outra, relativizamos a tendência a homogeneizar as observações relativas a fenômenos associados à violência, compartilhamos com a noção de cultura do medo proposto por Luiz Eduardo Soares ${ }^{4}$, ou as formas de percepção e de representação social da delinqüência, do crime, da violência, dos delitos, dos riscos.

Assolados por discursos milenaristas de fim século, talvez estejamos perdendo de perspectiva as razões sociais e culturais complexas que movem nossas interpretações

\footnotetext{
${ }^{2}$ Segundo L.E. Soares, "Sociedade Civil, movimentos sociais e mundo globalizado", in: Comunicações do ISER, n 49, Ano 17, 1998. "Fazer um diagnóstico negativo e elaborar um prognóstico pessimista são práticas correnets e extremamente valorizadas, no Brasil. Não importa que a previsão se mostre equivocada, no futuro. O erro não porá em risco a respeitabilidade do profeta. Se o profeta é pessimista, será sempre respeitado."

3 . MARTUCCELLI, Danilo. "Reflexões sobre a violência na condição moderna". In: Revista de Sociologia da USP Tempo Social, volume II numero 1, maio de 1999, p. 172

4 . SOARES, Luiz Eduardo. "Violência e cultura do medo no Rio de Janeiro". Palestra proferida no PPGAS, IFCH, UFRGS, Porto Alegre, 1996.
} 
científicas do mundo social, das noções de democracia e cidadania, assim como da própria figura humana, na contemporaneidade.

Em plena era da globalização, os processos de difusão e disseminação de valores e emoções mediados pelos meios de comunicação e pelas redes virtuais, embora apresentem facetas negativas, podem por sua vez também gerar outras potencialmente positivas. Isto se entendermos que o mass media não substitui ou elimina outros universos específicos de aprendizagens e socialização das pulsões coletivas e individuais, como o caso do grupo familiar, das associações, da escola, dos partidos políticos, dos sindicatos, das instituições de trabalho, das redes de lazer, dos pertencimentos religiosos, etc..

Embebidos que estamos por uma cultura que cria e expande a "lógica perversa do medo e de seu ciclo vicioso", toda a sorte de atos cruéis mediáticos, banalizados por muitas análises ditas "cientificas", são tornados processos simples e unidimensionais. Desta forma, perdendose a perspectiva complexa e multimensional da violência, as imagens projetadas pelos meios de comunicação são como um "apertar de gatilho" que arrancaria os plácidos jovens membros de uma pacífica comunidade de sua condição civilizada, jogando-os na barbárie de seus sentimentos mais torpes e seus estados de alma mais inferiores.

Estas discursividades não podem ser afirmadas como dados científicos, distantes que estão da identificação objetiva de práticas e fenômenos identificados violentos porque "referentes de processos empíricos dos fenômenos da criminalidade"s. Há de se dar conta que o problema da violência na modernidade encontra-se na "auto-representação normativa que as sociedades modernas querem dar de si mesmas. É neste sentido preciso que se deve interpretar a violência como um limite físico ou material no próprio coração da modernidade" ${ }^{6}$

Sujeitos ao sensacionalismo e às manipulações políticas, as análises dos meios de comunicação retornam ao anti-humanismo do pensamento político hobbesiano (que trata do instinto egoísta do animal humano), agora na feição deformada do desencantamento de uma “civilização da imagem” à respeito da ética da responsabilidade que a ajudou a fundar, presidida pela sua crença desmedida no progresso do conhecimento técnico e da razão.

A tecnologia é cada vez mais assolada pela suspeita. Face ao nascimento de regimes totalitários, ao longo das primeiras décadas do séc. XX, a Escola de Frankfurt será aquela responsável por recriminar moralmente, em especial, a indústria cultural por ser ela culpada do descontrole das paixões humanas mais torpes. Inspirados, portanto, pelo moralismo

\footnotetext{
5 . SOARES. 1996.

6. MARTUCCELLI. 1999.
} 
modernizador e pessimista de épocas passadas, transformado, agora, em mais um sistema de crenças e de valores, muitos intelectuais saem em defesa do cidadão, conceito acoplado à figura do consumidor, em sua cruzada contra à violência no cinema, na propaganda e na televisão, por esta ganhar matizes de realismo sádico. Não há dúvida da intencionalidade perversa de uma análise unidirecional. A violência exercida pelo poder, pelas classe dominantes repousam numa legitimidade que não se estende às manifestações de baixo para cima, de grupos desfavorecidos. Esta perspectiva evidenciaria uma crise da significação da violência e do processo de supervalorizar a informação (o consumo da informação politicamente correta) como redentora da violência desmedida.

Presa a uma armadilha moralista, alguns intelectuais partem, com hostilidade vociferante, contra os meios de comunicação, por sua "natureza" perversa, ou seja, por sua propensão à esfumaçar os tênues limites entre realidade e fantasia e à deteriorar "estados de consciência”. Assim, os críticos do mass media, de modo unidimensional, associam o meio à mensagem que vincula, por seu apelo desenfreado "à agressividade, a dessensibilização, a passividade e o vício pernicioso", para, logo após purga-lo de seu valor nefasto, lhes atribuir o papel estratégico de socialização positiva para a vida coletiva e de formadora de consciência cívica. Estranho, não?!

Os programas governamentais que fomentam a "aprendizagem à distância", através da implementação de aparelhos de televisão nas salas de aula ou de informatização da escola, ou seja na mídia como locus de uma proposta didático-pedagógica revolucionária, encaixam-se perfeitamente neste caso paradoxal que gravita da crítica contumaz à exaltação "responsável" dos meios de comunicação. Assim, se certos filmes, jogos eletrônicos e programas de televisão, induzem crianças e jovens à maldade e à violência, levando-os a participar do ato imoral de assistir a dor e a agonia alheia, seja em programas de televisão, seja em filmes de ação - ou em jogos eletrônicos- , e a tornarem-se intolerantes e embrutecidos face ao sofrimento do seu semelhante, sem limites do que é socialmente correto; outros, os "programas educacionais", os levam para o "bom caminho", "salvando a alma da danação"!

Há que se dar conta que são as discursividades sobre a violência que buscam amarrar de forma direta a absorção de cenas de violência à progressão da criminalidade, sem avaliar a percepção das pessoas frente a mesma.

Numa revista de circulação pretensamente científica, uma reportagem tratava da visão de eminentes professores e pesquisadores dos EUA que discorriam sobre as "aulas de assassinato no computador" que alguns jogos eletrônicos forneciam aos seus usuários mirins. A argumentação central da reportagem era construída em torno da demonização dos jogos 
eletrônicos, muitos deles recriando as ambiências de filmes de ação comercializados em salas de cinema comparando-os, inclusive, aos jogos simuladores usados em treinamentos militares destinados a capacitar soldados para situações de guerra e de combate eminente.

Os comentários dos "especialistas", aludindo a uma pretensa sedução da violência solitária, eram ricos de expressões de cunho moral sobre os usos indevidos das tecnologias audiovisuais ("vulgarização da barbárie", "banalização da violência", "técnicas de condicionamento", "sadismo virtual", "vitrine de sangue e horror", "passatempo dissociado das conseqüências morais"), mas de uma simplicidade pungente que chegava a estarrecer o leitor mais atento.

Repleta de afirmações e dados "científicos" - "videogame estimula os reflexos mas adormecem a consciência", "quanto mais o grau de violência, mais sobe a pressão arterial", "durante o jogo, o inconsciente e as emoções predominam", "a repetição pode causar doenças como a tendinite", "essa pobreza de estímulos audiovisuais requer pouco os estímulos sonoros" - a reportagem, aprisionada numa cultura do medo, incitava à opinião pública a associar, de forma reducionista, a dramaticidade da violência aos jogos de computador. A associação, difundida pela mídia, entre violência e jogos eletrônicos reforçava, pela mesma estética apelativa, a visão caricatural do filhote robotizado do homem contemporâneo que pretendia combater, num tom de fim de milênio, digna ao filme Armagedon, estrelado pelo sempre "duro de matar", Bruce Willis.

Lendo a reportagem, recheada de "efeitos visuais" e entrelaçados de uma retórica aterradora, percebe-se o quanto a violência para os "cientistas" pressupõe um déficit de informação. Tentando reduzir a violência à esta representação, só nos resta apelar para a desconfiança desta condição moderna como forma de sufocar atos desmedidos e primitivos de energia, ao ver-se que, a própria matéria "simulava", através de imagens editoradas por programas de computador, a ambiência nefasta e os danos causados por jogos eletrônicos à "raça dos humanos". Numa linguagem visual próxima da estética do grotesco e do monstruoso dos próprios jogos de videogame que eram objetos de crítica, tornava-se impossível não pensar a convergência entre a violência dos jogos eletrônicos citados e a retórica da violência empregada pela própria revista para abordar o tema em questão.

Recriada a atmosfera assustadora de violência, na mídia escrita, a reportagem reforçava, de forma implícita, a mesma imagem da desumanização e a mecanização do ser humano tão criticada para o caso dos jogos eletrônicos. Por derivação, reduzia-se, assim, os leitores da revista às mesmas reações típicas de animais que eram diagnosticadas para os "micreiros" viciados na tela de computador. Pensando estar imune aos figurinos do imaginário de uma 
cultura do medo dos meios audiovisuais, a reportagem disseminava uma visão distorcida da mídia eletrônica, agora sob a forma hiperbólica, oscilando entre o fascínio e repulsa por uma visão despótica da imagem e da tecnologia.

Sem dúvida, diante da presentificação da imagem obscena da violência no cinema, na televisão ou nos jogos eletrônicos, somos confrontados ao regime de hostilidade da própria vida social em que estamos submersos. Assim, melhor será diabolizar a imagem produzida pela tecnologia eletrônica ou digital que está fora de nós do que refletir até que ponto a imagem técnica (fotográfica, videográfica, fílmica, etc.) e, dentre elas, principalmente, a imagem em movimento, guarda em si mesma o poder de nos interrogar acerca de nós próprios. Isto nos estimula a questionar sobre as representações gerais da violência, que desta forma nega a diversidade de suas manifestações e das formas singulares de compreendê-las, como o propõe Gilberto Velho. Por que a sensibilidade do consumidor estaria mais atacada à imagens ficcionais de violência do que aos ataques cirúrgicos dos EUA à povos inimigos?

Sem dúvida, a imagem técnica nós podemos exorcizar, perseguir, queimar, torturar e exterminar, atribuindo-lhe, via uma processo de naturalização, capacidades ético-morais humanas, uma vez que mais dor causaria ao sujeito portador de "boa consciência" ater-se aos usos e abusos que se ele faz dos seus atos de violência na vida cotidiana, talvez indiferente à banalidade da miséria, da fome e da pobreza quando as avista do alto de seu condomínio horizontal, protegido por grades, porteiros eletrônicos e guardas.

Piegismo, diriam alguns! Pode ser, mas nunca é o bastante evocar a fragilidade da figura humana face à perda de sua dignidade. Portanto, vale aqui se pensar até que ponto a imagem produzida e criada pelos meios audiovisuais e, posteriormente, veiculada em produtos culturais típicos do consumismo contemporâneo como as novelas, os filmes, os programas de auditório, os documentários jornalísticos, as mini-séries, os jogos eletrônicos, e tudo o mais, não traduzem especularmente as formas de vida sociais onde são geradas.

Nem boas, nem más, as imagem retratadas pelas tecnologias audiovisuais são um terreno fértil para se compreender o grau de integração ou desintegração dos arranjos da vida social que se vive hoje, permitindo a todos quanto dela fazem parte ver-se em todo o seu esplendor ou decadência. Portanto, quer isto seja palatável ou não, os meios de comunicação não podem ser compreendidos em sua complexidade sem que se perspective sua eficácia simbólica no interior do contexto semântico onde se gera a sua linguagem tanto quanto no cômputo geral do circuito informacional em que se dissemina. ${ }^{7}$

\footnotetext{
${ }^{7}$ Cf. A Novaes, Rede Imaginária, São Paulo, Cia das Letras, 1991.
} 
Logo, torna-se impossível se discutir os meios de comunicação de massa como locus gerador de sentido ao consumismo da violência, sem levar em conta um estudo mais detalhado da correlata cultura do medo que dissemina no corpo social a criminalização da desordem e as suas respectivas estratégias de superação, pela via de intervenções bélicas, despóticas ou repressivas.

Trata-se igualmente de compreender as motivações e razões que sustentam as discursividades que recorrem aos meios de comunicação de massa com a recorrência banal à um Bestiário associado à máquina que gera e produz imagens, tido e visto como verdadeiro Ogro a devorar mentes sadias e corpos dóceis. Propomos assim, um deslizamento do tema da violência conjugada à mídia para enfocá-la na própria produção de saberes sobre o tema que a representam intrinsecamente associada a um processo de demonização do consumo de imagens e de tecnologias audiovisuais. Por que não sugerir este viés como uma linha de estudo a ser privilegiada pela antropologia, campo de conhecimento com familiaridade teórica para investigar as estruturas do imaginário e seus regimes de imagens projetados no contexto do mundo urbano contemporâneo pós-industrial. ${ }^{8}$

As imagens que associam os meios de comunicação ao despertar dos sentimentos de animalidade e bestialidade no interior do próprio homem contemporâneo, conclamam ao antropólogo a interpretá-los segundo o simbolismo da queda moral e do pecado. Isto é, à regressão do homem contemporâneo a temas tão caros à tradição judaico-cristão como foi o caso da luta que a Igreja travou, (e que trava ainda no Brasil,) contra o catolicismo popular, a presença insidiosa do culto e devoção às imagens no interior de seus rituais de vida coletiva.

Sem dúvida, como inúmeros teóricos da linguagem audiovisual apontam, o realismo sensorial atribuindo à imagem cinematográfica, televisiva ou eletrônica, que restitui aos seres e às coisas a sua duração em "tempo real", engendra no seu espectador, o sentimento da vida concreta e a percepção da realidade objetiva. Por isto, e muito mais, é que cinema, televisão e jogos eletrônicos são, mais que a fotografia, máquinas "indigestas" que nos devolvem emoções reais, muitas vezes ressentidas e encobertas, tanto de ordem coletiva quanto de ordem pessoal. ${ }^{9}$ Para o melhor ou para o pior, é através de tais tecnologias que a violência presente à vida ordinária adquire visibilidade, transparecendo a parte sombria dos valores sociais, éticos e morais que sustentam a vida coletiva contemporânea, sobretudo se nos atermos aos indivíduos situados em escalas sociais médias e abastadas protegidos da violência por

\footnotetext{
${ }^{8}$ Cf. G. Durand, Les structures anthropologiques de l'imaginaire. Paris, Dunod, 1984.

${ }^{9}$ A propósito, consultar A Machado, Imaginário e Máquina, São Paulo, EDUSP, 1993.
} 
mecanismos objetivos impessoais e por meio de relações altamente personalizadas. Como o esclarece Martuccelli, inversamente os meios desfavorecidos se caracterizam pelo fato de serem pouco protegidos por mecanismos impessoais face à insegurança, e de serem raramente auxiliados quando sobrevém o perigo (aliás, muito mais freqüentemente do que nos grupos abastados) por uma assistência personalizada. ${ }^{10}$

Neste sentido, é a representação figurativa dos dramas sociais contemporâneos que tais tecnologias perfomatizam (violência, brutalidade, intolerância, crueldade) que choca o olhar mais aguçado, uma vez que as imagens veiculadas restituem ao espectador uma presença, até então, tornada pretensamente ausente, na vida ordinária.

Mas para qual presença apontam não só as imagens de violência na TV, mas à própria imagem dos meios de comunicação no imaginário do homem ocidental, hoje? Para a presença do duplo do paraíso consumista da sociedade contemporânea e sua parafernália tecnológica assim como para o duplo da sua crença desmesurada numa mitologia do progresso e técnica.

A imagem da violência mediatizada através dos meios de comunicação, pode ser tomada como o duplo da visão do paraíso que a própria sociedade tecnocrática e industrial gera em seu interior: Se, por um lado, tais meios anunciam a presença do consumerismo da violência, insano ao homem contemporâneo, por outro, eles também manifestam a presença dos próprios atos de violência deste mesmo homem no mundo.

Sendo assim, a imagem televisiva apresenta todos os caracteres da vida real tanto quanto releva a presença humana no mundo. Portanto, se apontamos a presença de uma verdade subjetiva de violência, fora dos limites, em certos jogos eletrônicos, esta presença manifesta, por sua vez, a exterioridade material da violência descontrolada no corpo da própria sociedade contemporânea.

Desta forma, se criticamos, muitas vezes, certos filmes, programas de televisão, filmes ou jogos eletrônicos, atribuindo-lhes responsabilidades ético-morais humanas na área das aprendizagens da vida social, é porque eles representam, de formas diferenciais, o "espelho da alma" do mundo urbano contemporâneo, estampando, tal qual uma vitrine, as pulsões individuais e coletivas de uma sociedade habituada a reconhecer, em seu percurso civilizatório, apenas a violência instituída no corpo social através do monopólio do Estado, ignorando a sua presença de tais "privilégios" concentrados em determinados arranjos da vida coletiva. ${ }^{11}$ Como não perceber que é próprio do percurso da modernidade, a conformação de

\footnotetext{
${ }^{10}$ MARTUCCELLI. 1999. P. 168 e 169.

${ }^{11}$ A respeito da sociogênese do monopólio da violência pelo Estado, da passagem do constrangimetnomsocial da violência ao constrangimento da violência no plano da construção das subjetividades, no interior da dinâmica da civilização ocidental, ver Elias, N. La dynamique de 1’Occident, Paris, Lamann-Lèvy, 1975 e La civilisation des moeurs, Paris, Calmann-Lévy,
} 
uma premissa normatizadora onde os indivíduos em processos sociais interiorizam valores e normas que na sua exterioridade, configuram sua "personalidade". Não poder responder devidamente à estes valores ideais, como no caso de uma ação violenta, é então atribuído aos erros na socialização, nas falhas de motivações ao controle das pulsões. Como negligenciar as estruturas elementares do mundo externo institucionalizado que credita no social seu modelos de regras, valores, normas que asseguram sua reprodução. Como não enxergar no projeto civilizatório de autocontrole a violência da trajetória gradual de desfiguração do homem, condenando-o para sempre à conquista de autonomia, do domínio da emoção pela razão,

Habituados que estamos, na cultura do Ocidente, ora a "coisificar" a imagem, atribuindo-lhe uma função de duplo sensorial (idolatria), ora a "degradar" o saber que ela representa, espécie de objeto fantasma e fonte de erros, pela via de um pensamento que se quer purificado da poluição das imagens (iconoclasta), tornamo-nos incapazes de ver, na maioria dos casos, a coerência funcional entre o pensamento simbólico e a representação conceitual que ela encerra. Por que não atribuir ao espectador, ao receptor, ao consumidor uma multiplicidade de leituras, interpretações e assimilações possíveis que podem variar desde a produção de um tempo de significação de existência até a simples eficácia de experienciar sensações instantâneas.

A fixação no consumismo de imagens de violência pelo homem contemporâneo, e propagadas pelos meios de comunicação, não se explicam através de razões ligadas a constrangimentos ou intimações psicológicas ou sociais uma vez que elas cumprem um trajeto que oscila dos imperativos pulsionais universais do sujeito humano às intimações objetivas que emanam do meio social e objetivo.

Antropoformizar os meios de comunicação e a tecnologia que lhe dá suporte em razão da representação da violência que eles veiculam, torna-se, portanto, o caminho mais fácil para reduzir a imagem técnica apenas ao campo da reprodução das motivações psicológicas e culturais da sociedade contemporânea, ignorando-se as motivações simbólicas que a miséria, a guerra, a pobreza, a violência e a fome engendram no complexo cultural que rege a cosmologia contemporânea e, no seu interior, a figura do homem da civilização.

$\mathrm{O}$ esquema da animalidade associado à repulsa de muitos intelectuais aos meios de comunicação, ligando-os aos sentimentos poderosos de bestialidade e da agressividades, referem-se, sem dúvida, à sua recusa em operar com as mais primitivas pulsões associadas ao animal humano recobertas no plano da teia de significados desta cultura.

1973. Sem dúvida a obra de Foucault, A microfísica do poder, é aqui também referencial, embora dentro de uma outra perspectiva. 
Sobredetermina-se, assim, na sociedade contemporânea, as imagens de repulsa aos meios de comunicação. Designamos, genericamente, aos meios audiovisuais poderes demiúrgicos para além do que a simples tecnologia pode fornecer: tornar a todos bons ou maus, por suas características intrínsecas. Atribuímo-lhes, pejorativamente, a idéia de um cosmos mecanizado, impessoal. Tais pensamentos e ações no que se referem as tecnologias audiovisuais são, entretanto, coerentes com uma sociedade tecnocrática que tende a desfigurar à imagem do homem, e isentam à todos de suas responsabilidades sociais na produção da violência: governos, políticos, cidadãos, produtores, realizadores, consumidores, etc..

Entretanto, as tecnologias audiovisuais possuem, como tantas outras produzidas pela engenhosidade humana, qualidades antropocosmomórficas, justamente porque nelas o homem contemporâneo se afirma e reconhece-se a si mesmo, projetando o seu interior no mundo. ${ }^{12}$ "Animais totêmicos" da sociedade contemporânea, o cinema, a televisão ou os jogos eletrônicos, podem ser interpretados como espaço de recriação e re-conhecimento de uma mitologia singular do mundo ocidental pós-industrial na medida em que permitem reconhecermo-nos, através deles, com atributos da humanidade, mesmo que seja uma certa humanidade desencantada de si mesma.

Talvez esteja ainda por se fazer um estudo aprofundado da violência na mídia que revele, de forma responsável, o quanto os meios de comunicação, reúnem a figura do homem contemporâneo ao seu cosmo mecanizado (espelho e miniatura) tanto quanto, por vias muitas vezes perversa, dissemina no mundo seus atributos singulares.

Anunciar, como foi o caso da reportagem sobre o Xingu, na Revista Veja, Xingu, de 30 de julho último, os guardiões do verde, a entrada da televisão como potencial disseminador da violência entre as tribos que habitam esta reserva, para logo após exaltar a atitude de censura dos caciques locais a tais meios de comunicação, considerados inadequados para suas crianças, é mais uma das formas irresponsáveis com que jornalistas e intelectuais tratam o tema da violência, sob a ótica da cultura do medo. Na trilha da construção da figura do "bom selvagem" no santuário do Parque do Xingu, a televisão novamente aparece, numa mídia dirigida às elites, em sua face distorcida.

O tema da violência entre as sociedades indígenas não passa simplesmente pela proibição de acesso do público infantil aos programas de televisão, mas pela presença de instâncias na vida social (competições, danças, festas e jogos) que permitem que os sentimentos coletivos e individuais hostis, agressivos e beligerantes, presentes à vida social,

\footnotetext{
${ }^{12}$ A respeito ver E. Morin, Le cinema ou l'homme imaginaire, Paris, Editions Minuit, 1958.
} 
encontrem seu lugar de expressão criativa no mundo, isto certamente, em meio a antenas parabólicas movidas a baterias solar, chinelas havaiana, calções de brim, lanternas e pilhas.

Compreender o consumismo da violência na mídia como, aliás, na ambiência escolar ou familiar, pode tornar-se, assim, sem muito eufemismo, uma visita aos pesadelos causados pelos impasses e obstáculos que impedem a resolução dos arranjos das formas ordinárias de vida social do mundo contemporâneo e pelos quais somos todos, direta ou indiretamente, responsáveis. 
